\title{
Key elements of a development strategy for the south of Serbia
}

\section{Introduction}

In Serbia, as in other countries in development, there exists an expanded awareness of the need for the formulation and implementation of strategy for economic development at the local and regional level. It is a particularly strong concern of the local actors in the Preševo municipality that, through an education process, innovation and co-operation (business and inter-ethnic alike) may both contribute towards accomplishing an advanced and stable society.

In that context, local self-government and American partner organisations have recognised the importance of the production of strategy documents that assist in determining a long-term plan for evolving an economic perspective and a scheme for municipal development as regards undeveloped municipalities in the Republic of Serbia. This kind of document comprehends numerous activities directed towards making a better environment in which local economic development might take place.

First amongst the activities is a diagnosis of the state of the problem, the development of alternatives and the establishment of where a competitive edge might lie.

The diagnosis of the state of the problem considers the following steps:

1. the identification of all stakeholders important to local economic development with their level of significance and the potential they offer for the production of a strategy for local economic development

2. the identification of the problems, potential, limiting factors and opportunities concerning the Preševo municipality as regards local economic development

3 . the active participation of all actors in the sense of discussions, suggestions, initiatives, all for the cause of adequate and purposeful local economic regeneration.

In particular, it must be mentioned that, besides the production of local economic regeneration, a Strategy for Preševo municipality has been installed, as has a QMS (Quality Management System) in municipal management with a view to increasing the working efficiency of the operating bodies of local administration. This has all been done to ensure a more qualitative service both for the people and for business organisations. The municipality of Preševo is the first in the Republic of Serbia in which a quality assurance system has been installed.

Furthermore, empirical research has been conducted into the concerns of the people of Preševo regarding the establishment of their own businesses, while public opinion about the possibilities, conditions and pretexts for the development of family businesses in this municipality has also been examined. Research was carried out by a random sample of 2000 interviewees and the research results will be used in the subsequent period by the local administration, foreign donors and the bodies of the Republic of Serbia which represent the relevant factors. They are the ones who are most responsible for the consequent implementation of this long-term strategy of local economic development. 
During the production of the strategy, training and education for entrepreneurs and ordinary people alike who were interested in starting up their own businesses has been realised with the following themes:

a. international negotiations and protocols

b. how owner-businesses should be started and improved - from concept to realisation

c. installation of quality management systems under the ISO 9000 standard; environmental protection management systems (EMS) under the ISO 14000 standard; and HACCP - risk analysis and critical points of control

d. team working

e. active employment search.

All the activities that have been realised refer in the first place to detailed analyses conducted from exclusive suggestions drawn from amongst the range of competent stakeholders.

\section{Diagnosis of conditions in the municipality of Preševo}

Preševo municipality is one of the most undeveloped municipalities in Serbia and has a top-ranking priority in the development policy of the Republic. Over many decades, Preševo municipality has been confronted with a high rate of population growth. In the 1948-1991 period, the total population recorded a growth of $66.6 \%$ (expanding from 23279 people to 38 943) while, in the period from 1961, the total population has expanded by $41.3 \%$. It should be said that the dynamics of such growth are inorganic as a result of migration factors: in the period to 1960, the rate of growth was $1.17 \%$; up to 1970 it was $1.22 \%$; up to 1980 it was $1.86 \%$; and, in the period to 1991 , it was $2.11 \%$. In the last decade, the net rate of emigration was lower and, therefore, emigration processes did not have the same significance in factor analysis of population growth that they had in the 1970 s.

The economic situation for the municipality of Preševo is marked by the following main considerations:

- there is a high degree of agricultural labour as a proportion of the total population $(39.8 \%)$

- the active labour force capable of employment is under the strong influence of the younger population (48.3\%, around the average for the Republic in 1995)

- every third worker is employed outside the formal economy (37.3\%), while in the structure of employees within the economy, $45.6 \%$ is employed in industry

- the coefficient of unemployment is extremely high (at $64.2 \%$, it is higher than the average for the Republic)

- the population has weak economic power (active basic elements per inhabitant were only $11.6 \%$ of the Republican average in 1995, the retail market stood at $65.3 \%$ while original budgetary revenue per inhabitant was $49.6 \%$ of the Republican average) and the economy itself is insufficiently developed (the transportation infrastructure and hydro-electric power are poor, while only one in every fifteen inhabitants has a telephone)

- the social infrastructure is also in need of development: there are 1274 inhabitants for each doctor, while other indicators are around half the average for the Repub- 
lic; the exception is the amount of resources put into basic education per student which was, in $1995,83.4 \%$ of the Republican average.

These represent the most significant starting points from which the municipality commences its new phase of development. The basic development problem is that the municipality of Preševo has not succeeded, over a relatively long period (it has held the status of being an insufficiently developed area for more than three decades), in building the basic development presuppositions that could provide a solution to these vital problems and in attending to the essential steps in the maintenance of development.

\section{SWOT analysis of developmental opportunities in the municipality of Preševo}

Dynamically envisaged, the entire development of the municipality of Preševo is determined today, almost in total, by investments secured from the Republic and affected in their internal implementation by low efficiency, personnel issues and organisational weaknesses.

A development unit within the Institute for Small and Medium Enterprises has been conducting SWOT analyses, looking for comparative advantages and drawing conclusions on a few strategic goals and the development opportunities of Preševo municipality. SWOT analysis represents an established instrument in strategic planning, assigned for the identification of comparative advantages and, in addition, basic municipal weaknesses as far as the main inputs are concerned - i.e. those factors which inhibit development. Generally, a SWOT analysis is a review of internal strengths and weaknesses, and those opportunities and threats that are under the influence of external factors. In the sense of a SWOT analysis, we can list under strengths all the internal factors that have a positive influence on the position of the municipality of Preševo and in the creation of regional comparative advantages. Internal factors that have a negative influence on the position of the municipality of Preševo are defined as weaknesses. Opportunities arise from the better use of strengths or understating the weaknesses as regards the positive influence of external factors. Threats are identified as expected but unfavourable external influences on the position.

In this defined manner, SWOT analysis, together with deep-rooted assessments of the present situation, provides the basic elements of the definition of strategic aims and priorities, as well as the parameters of their justification.

SWOT analysis comprehends the following strategic factors for the development of the municipality of Preševo in the next ten years:

1. agriculture

2. human resources

3. living conditions in rural areas of the municipality

4. tourism and services (tourist resources, service accessibility, the tourist offer and marketing)

5. development of small and medium enterprises

6. infrastructure and environmental protection. 


\section{Definition of developmental policy}

After undertaking a diagnosis of the conditions, problems, development possibilities, needs and competitive advantages, we have directed our activities towards defining a developmental policy for Preševo municipality. This comprehends the production of vision and mission statements for the municipality and the determination of its strategic aims as the key questions in local economic strategy and infrastructural and institutional development.

To open up a discussion about the growth and development of the municipality of Preševo, i.e. about the development strategy, we will define what the development policy is, within which the development strategy is just one element. The development policy represents an assemblage of programmes, principles, positions and criteria on which the process of bringing decisions about the direction, methods and speed of the growth and development of the municipality may be based.

The development policy has been set for the long-term and, as such, is related to a period over which very significant changes in the development orientation of the municipality can be achieved concerning its position within the wider region and its influence on social development as a whole.

If the municipality is to accomplish this development policy in the long-term, it has to determine a strategy for its realisation, i.e. a development strategy. The development strategy has an orientation character, showing the municipality the path it will take to reach its development aims.

The development strategy of Preševo municipality requires the significant expansion of its dimensions - i.e. its range of activities - in all areas. The development plan is the basis for defining a mutual vision for the future and the actions that need to be taken in accomplishing that defined vision. The development strategy is the guide that will help the municipality in determining activities in different areas as regards the individual institutions and, in that way, it secures a basis of operation for every institution which, by its human and material potential, gives support to the implementation of the vision for the development of Preševo municipality. The process of production of the development strategy for the municipality has in mind the definition of the municipality's economic future through its viable and balanced development.

\section{Vision of the municipality of Preševo}

The vision of the municipality of Preševo in the next decade (2005-2015) is to become an economically viable, environmentally clean, industrially developed and tourist-minded municipality, with an equipped infrastructure related to transport requirements, so that, by 2015, it is in a position to become the leading municipality in the south of Serbia and in the region. Quality is the only unlimited resource that could encroach on the accomplishment of this vision and it represents both the basic starting point and a guideline.

The vision of the municipality of Preševo is to become a space that will offer its inhabitants better economic, social, cultural and political conditions for their work and lives, and its business leaders the prospective conditions for dynamic development. The defining vision of the municipality is based on the genuine development possibilities and presuppositions over the following ten years; however, all this may be accomplished only if the strategic steps towards that vision are actively conducted. 


\section{The mission of the municipality of Preševo}

The mission of the municipality of Preševo is that the local administration should become a true representative of the political will of the people so that it may, by respecting the principle of good management, work on a better service offer to the people and for an increase in its quality through:

- infrastructure construction

- increasing the level of human capabilities in the local administration

- raising the level of technical capability

- protection of a healthy environment

- removal of existing and potential pollutants

- establishing the conditions for economic development and the growth of small and medium enterprises

- establishing the conditions for tourist development and better transport connections

- establishing the necessary conditions for the municipality of Preševo to become an economically viable municipality

\section{The values of Preševo municipality as a basis for the realisation of the vision, mission and strategic goals}

Municipal values are very important for the vision since this must be founded on clear and accepted values. The vision, mission and strategic goals of the municipality of Preševo will be supported by the following values:

- responsibility for economic prosperity (increasing the fiscal capacity of the municipality and forming a balanced municipal community)

- innovation (encouraging initiatives that lead to the betterment of the municipality and establishing the conditions for the achievement of this)

- professionalism in work (offering quality services to the population)

- responsibility for environmental protection (making efforts to protect the environment and to remove potential and existing water pollutants in the land, air, animal and vegetation spheres)

- development of the small and medium enterprise sector (reduction of bureaucratic requirements during their establishment period)

- respecting the needs of all the inhabitants of the municipality (insistence on meeting the obligations for the wide and various needs of the people)

- team working (working in full co-operation and a collegial spirit, by encompassing a wider circle of users in the decision-making process)

- solidarity (helping everyone who is in a state of social need)

- love and affection towards Preševo (endeavouring through the different phases of co-operation that a large number of people originally from Preševo may return and be included in development projects); to establish the conditions by which the Preševo diaspora could be attracted to invest in its homeland.

\section{Strategic goals}

The temporal horizon for the municipal vision is envisaged as a ten-year period. The strategic goals are formed as genuine possibilities during this expected period. As such, they should have wide acceptance, be obvious and not too distant from five to 
ten years concerning the speed of their realisation. The strategic goals of the municipality of Preševo comprehend the following:

1. improving the quality of the service offer to people (the municipality of Preševo will work on the recruitment of civil servants and the professional training of municipal employees, the technical equipment behind service provision and the inculcation of ethical business behaviours in all employees)

2. the maintenance and improvement of the existing level of environmental development (the environment of Preševo is quite preserved, so it is necessary to work on making all the conditions that will move the municipality closer to the ideal Preševo as an environmental municipality) so it could be joined in line with other environmental municipalities; this would deliver the production of organic foods and the development of tourism in Preševo municipality

3 . in developing the infrastructure to prevent the continued slowness of economic development and to improve the quality of life of the population, the following steps need to be taken:

- securing the quality of supply of electricity to the economy, institutions and the people

- improving the transport connections of the municipality with the surrounding areas and inside the municipality

- improving telecommunications connections

a improving the supply of drinking water to the people

- developing a permanent solution to the removal of solid public waste

- improving public services.

4. establishing the conditions for a more rapid local economic development: the local economic regeneration of the municipality of Preševo will be established on the basis of the:

- development of small and medium enterprises

- activation of already existing capacities and the speeding up of the process of globalisation

- production of organic food on the basis of raw materials drawn from the local area

- use of the forests and woods, i.e. the collection of forest fruits and medicinal herbs

- development of tourism (hunting, transport, school, ethnic)

- institutional organisation of manufacturers into alliances and clusters

- organised approach to the market based on modern marketing principles.

5. reduction of transport isolation - by building Corridor 10 and the main M25 road, as well as reconstructing local and regional traffic infrastructure, the recent relative traffic isolation of the municipality will be reduced with new main roads and railway directions

6. stopping the emigration of the population - by realising the previous strategic goals, the conditions for schooling, employment and the permanent residence of young people in this area, and in particular the return of citizens in mountain villages, will be improved 
7. improving socio-economic and cultural conditions in the round, in order to provide a better quality of life - better conditions will be made, via the realisation of the previous strategy, for socio-economic and cultural advancement as essential conditions for the general improvement of quality of life.

\section{Strategic priorities, measures and instruments for improvement of economic, infrastructural and institutional development of municipality Preševo}

The development destination of the municipality of Preševo, based on its defined vision, is the affirmation of the entire municipal space within the particular natural ecosystem; its more rapid integration into regional and Republican developmental flows; the development of small and medium enterprises; the use of raw materials from the local area; the production of organic food; and the improvement of the infrastructure via the development of tourism and better links to the most important traffic arteries. By organic development and improving social standards as regards general living conditions, the municipality of Preševo will contribute to a reduction in joblessness and the return of its citizens from various parts of the world and, in that way, will overcome the problem of an ageing society.

Strategy is the science and skill of determining, for any type of action, the main point of attack with which to accomplish the goals and aims. The strategy of development for the municipality of Preševo must, as in all other strategies, determine its points of attack (the strategic questions essential to success). The strategic priorities are those specific goals which are dedicated to the improvement of key areas that are influential as regards the accomplishment of previously-defined long-term strategic goals; they are the instruments within which existing resources may be deployed to fulfil defined goals.

The strategic priorities and questions have to be followed by specific measures that represent the guidelines for the necessary activities in the field and which will directly contribute to the realisation of the defined priorities and strategic goals. On the basis of all the above-mentioned developmental goals of the Preševo municipality, the following strategic priorities can be formulated:

\section{Sectors towards which development should strive and seek to fortify in order to achieve local economic regeneration and reduce unemployment}

- production of organic foods on the basis of raw materials from the local area

- strengthening of primary agricultural production, including both sheep farming and cattle-breeding, with a perspective on opening more livestock farms

- strengthening of agricultural processing capacities (opening of new cold storage and capacities for the processing of potatoes, noodle production, etc.)

- cultivation and the gathering of medicinal herbs and forest fruits

- production of mineral drinking water (MZ Cerevajka), and other available natural raw materials

- tourist development (transit, hunting, ethnic and health)

- rational use of the woods and forests

- organising manufacturers into alliances and other professional organisations for the benefit of the better and more harmonious use of resources and the expansion 
of the offer, as well as the organised presentation to the market in the country and the region.

\section{Measures that will have a short-term effect on local economic regeneration and the reduction of joblessness}

- the activation of existing capacities (either currently working at under-capacity or else not working at all) through appropriate privatisation so it could have a direct effect on local economic regeneration

- expansion of the utilisation of prevailing small and medium enterprises

- the establishment of new small and medium enterprises in the area of trade and services.

It is important to note that it will be necessary to secure qualitative financial means (i.e. loans from international institutions and the Fund for Development of the Republic of Serbia, for instance) to solve these strategic economic priorities successfully.

\section{Strategic priorities in infrastructure development}

Municipal infrastructure development by which short-term and medium-term local economic regeneration processes could be strengthened include as follows:

- supplying areas of the municipality of Preševo with quality electricity supply through the reconstruction of high power and low power networks

- improving the local and regional travel network to create better conditions for more successful agricultural activity and the flow of merchandise, tourists and employees

- development and improvement of railway traffic

- development of fixed-line telephony capacity and of mobile telephony

- construction of tanks for the purification of polluted water.

\section{Public services that should be strengthened for the improvement of the quality of life of the people of Preševo}

To improve the quality of life for people in Preševo, it is necessary in the area of public services to:

- improve the water supply both in villages and suburban areas

- improve the coverage of Preševo by radio and television reception

- improve fixed and mobile telephony services.

\section{Infrastructure within the area of the preservation and protection of the environment}

Towards the preservation of the environment, it is necessary to organise in Preševo the following activities:

- improvement of the management of solid waste

- change the existing refuse tip, build a new one and protect it by sanitary methods

- to proceed with the construction of drains (sewage and water reservoirs)

- to start on works for purifying waste water 
- to continue with the arrangement of riverbeds and streams through certain villages; in time, to pursue the introduction of the supply of the gas across the municipality

- to purchase all the necessary equipment and means for maintaining roads and cleanliness in heavily populated places.

\section{Development of small and medium enterprises and sustainable development in the municipality of Preševo}

In the technological sense, it is important that small and medium enterprises are successfully adapted to technological discontinuance, to the rapid seizure of new products in the process of the diversification and de-mystification of production and to the need to install technological innovations. The environmental value of such companies is connected with a lower environmental impact, smaller urban concentration, land saving and human resources.

From the contribution aspect of small and medium enterprises in the development of the municipality of Preševo, several economic sectors evidently have the highest economic potential: processing of agricultural products; industrial production (especially production enterprises in engineering and co-operation); tourism; and electronics management. ${ }^{1}$

The principal task of the strategy for the development of small and medium enterprises and sustainable development in the municipality of Preševo is to create a framework for the creation of a sustainable, competitive and export-oriented sector, thus to secure the economic and social improvement of the municipality of Preševo that would be seen in practice in:

- increase in the living standards of the population

- significant growth in employment

- strong development of the municipality

- strengthened connections with neighbouring municipalities and regions.

The main elements of the development strategy for small and medium enterprises in the municipality of Preševo are:

- the removal of legal obstacles to business and to the establishment of and dealing with small and medium enterprises (an action point for the municipality, in co-operation with state institutions)

- the recommendation of measures from the municipality for easing the access of small and medium enterprises to sources of finance

- a reduction of the scope of the grey economy and, at the same time, the improvement of the environment in which newly-registered companies are dealt with

- promotion of activities in the local media connected with the development of the sector

- the securing of financial and technical help from foreign donors for the offer of support for the accomplishment of priority assignments in the development of the sector in the municipality of Preševo

1 Ivan Vajić (ed.) (2004) Entrepreneurial management, business plan and business programmes $1^{\text {st }}$ edition, Belgrade: Institute for the development of small and medium enterprises/Zagreb: Centre for investment. 
- the creation of a stimulatory legal and administrative business environment for the sector

- the informing of existing and potentially sustainable developments as regards the opening of new lines of credit for the development of small and medium enterprises

- the establishment of a municipal agency for the development of small and medium enterprises that will offer them expert help in their initial establishment and subsequent development.

We can define the development of an efficient, basic transport infrastructure, in which the priorities are traffic arteries, water supply, electrification and the development of telecommunications services, as the basic development postulate for small and medium enterprises in the municipality of Preševo. In addition, however, we need to focus on the strengthening of services for smaller companies through the establishment of generic and sector-specific institutions for support; the connection of services with active strategies for the settlement of particular needs; and assistance to the sector concerning mutual co-operation over establishing a local observatory to monitor existing and future knowledge and ICT needs, as has been identified by regional social pacts with representative participants. ${ }^{2}$

When we consider the principal strategic priorities, the expert team has defined the establishment of a free customs zone, or an industrial zone, on the territory of the municipality of Preševo. The current position is that the municipality of Preševo has defined arguments that are in favour of the realisation and establishment of a free customs and an industrial zone (including the proximity of the airports of Skopje and Niš, the territory through which Corridor 10 passes, and railway transport connections). In the following period, the municipality of Preševo will be attractive for the reasons of construction projects in connection with Corridor 10 which will open up possibilities for the development of the services sector and for the employment of the local population.

Within the aims of south-east European initiatives for co-operation (SECI, the initiation of the creation of better objects and means for transport across the length of Corridor 10), the development of motels, service stations and other facilities that would attract the development of additional jobs and companies - such as restaurants, truck stops, shops for car parts and retail services - takes on a clear priority. Advantage needs to be accorded to: multi-functional objects and means for transportation that combine trade transport centres and centres for welcoming tourists with promotional material and information about the region, brochures and unique products of the region that can be sold in shops; points for fuel and water; centres for lubrication and truck maintenance; and main buildings that could include: hotels; restaurants; shops for travel and other personal requisites; private bathrooms; dry cleaning; internet cafés; business services; ATMs; FAY; phone boxes; play rooms; fast food.

Objects and means for transport and services will be required, as promotional efforts will serve to expand the tourist market flow throughout the region and generate possibilities for the development of the business attempts of small businesses in the field of transportation to serve the travelling public. In potential co-operation are: 55

2 Grozdanić, R (2005) 'Entrepreneurs and placement' Economic Sights Belgrade. 
motels; 85 petrol stations; and 67 platforms. Alongside this corridor, it is estimated that over 20000 people will be directly employed in the construction phase while the total contribution to new employment will be close on 100000 new jobs.

A viable option for the development of trade transport centres and centres for welcoming tourists and the establishment of service stations is the creation of service contract agreements between public agencies and profit-oriented corporations through the setting-up of private-public partnerships at the local level. ${ }^{3}$

\section{Conclusion}

Documents comprising the Strategy for the local economic development of the municipality of Preševo are of great importance for this economically-undeveloped municipality in the south of Serbia since it defines the road that should be followed in the next decade. This strategic document represents a special indicator for relevant factors at the national level, as well as domestic and foreign investors, international organisations and donors, regarding the key resorts of Preševo and the sectors in which it is necessary to invest resources in order to accomplish higher profits and to maximise the use of existing potentials.

However, the real value of the strategic document will be best achieved if all interested stakeholders (the Republic of Serbia, investors, international organisations, donors, chambers of commerce and trade unions) start, without delay, the implementation of the strategic goals and priorities that define this document.

Upon the realisation of the strategy document, special attention should be paid to the numerous issues and damaging pre-conditions that mark the real economic situation of the municipality of Preševo. Data show that the infrastructure is in very poor shape; that the rate of unemployment rises over 50\%; that the conditions for the development of family businesses and the small and medium enterprise sector are very bad; that the process of privatisation is not complete; and that all of this shows us that, for the development of the development project of this municipality, consensus is needed from all interested stakeholders, starting from the Republic of Serbia, local authorities, trade unions, citizens - and all of that on behalf of economic development, new job opportunities and the enlargement of the attractiveness of this city for further investment.

It is necessary to have a more productive approach and to combine active measures on the labour market with measures at all levels for the stimulation of the setting-up of micro, small and medium enterprises. These provide examples for the development policy concerning the promotion of small companies and of self-employment, as well as the alleviation of the mobilisation of working power through training and relocation policies that are implemented in unison, i.e. where economic development supports the development of the private sector. In this way, the economy would be able successfully to support the development of the private sector so that the economy could successfully absorb unemployed people who are prepared for work by means of an active labour market policy and by the increase in municipal activities regarding the encouragement of domestic and foreign investment in both brownfield and greenfield areas. A framework for this type of investment will be the planned construction

3 ibid. 
of the free customs zone and the industry zone, business incubators and projects for the creation of clusters in the municipality where detailed elaboration and SWOT analyses can be carried out.

\section{References}

Grozdanić, R (2005) 'Preduyetništvo i zapošljavanje' Ekonomski vidici Beograd.

Brnjas, Z (2000) Strategijski menadžment Poslovni sistem Grmec, Privredni pregled, Belgrade.

Grupa autora (2004) Preduzetnièki menadžment Institut za razvoj malih i srednjih preduzeća, Centar za investicije: Beograd-Zagreb.

Dokument 'Strategije lokalno ekonomskog razvoja opštine Preševo' Institut za razvoj malih i srednjih preduzeća: Beograd, 2006.

Dokument 'Strategija razvoja Juga Srbije’ Vlada R. Srbije: Beograd, 2005. 